\title{
Adaptação e reconstrução: a ausência de Margaret D'Anjou no teatro da restauração
}

Gabriel Leibold e Leonardo Bérenger

O tiger's heart wrapped in a woman's hide! $(3 \mathrm{H} 6,1.4 .140)$

Propomos neste artigo uma leitura da adaptação teatral da peça shakespeariana King Richard III (1592) ${ }^{1}$, escrita por Colley Cibber (1671 1757) no período da Restauração da Monarquia Inglesa. Sob a luz do materialismo cultural, teoria que tem no acadêmico britânico Raymond Williams (1921 - 1988) um de seus nomes mais representativos, da análise historiográfica operada por Stephen Orgel e da crítica shakespeariana de cunho feminista, o foco desta análise é o tratamento dado a Margaret D'Anjou em relação às outras personagens femininas da peça de William Shakespeare (1564 - 1616) na adaptação de Cibber, consideradas como parte de um processo cultural ativo pertencente a uma cultura historicamente datada.

É fácil buscar exemplos de produtos culturais manifestamente transistóricos. Essas obras carregam consigo a cultura da qual se originam, são incorporadas e reincorporadas por outras culturas ao longo da história. O acadêmico britânico Raymond Williams, em seu livro Culture, salienta que "é possível dizer, no geral, que é inerente ao conceito de uma cultura sua capacidade de ser reproduzida; e, para além disso, que em muitos de seus traços, a cultura é em si um modo de reprodução" 2 (WILLIAMS, 1981,

\footnotetext{
${ }^{1}$ Doravante denominada R3Skp.

${ }^{2}$ Todas as citações traduzidas para o propósito deste artigo foram feitas pelos próprios autores.
} 
p. 184). De certa forma, a materialidade e continuidade de uma cultura se encontram nos processos ativos de reconstrução e reprodução de suas especificidades.

Muitas obras capitais são produzidas dentro (e, de certa maneira, por causa da existência) de formas ainda maiores no auge de seu desenvolvimento cultural. Um sentido comum de 'reprodução' pode diminuí-las, obras as quais em qualquer teoria geral devem ser vistas como produção importante, tornadas possíveis por meio de uma forma reprodutível. Além do mais, em casos diretamente opostos a esses nos quais os elementos formais prevalecem sobre um conteúdo específico, há trabalhos importantes que são, como foram, uma re-produção da forma: uma realização mais completa ou mais direta de suas possibilidades. (WILLIAMS, 1981, p. 198.)

Um dos movimentos de reprodutibilidade cultural mais profícuos no âmbito do indivíduo social ${ }^{3}$ ocorre por meio do gesto, em face ao passado, que resulta na adaptação. Ela pode ser desde uma reprodução de ordem formal com alterações significativas em seu conteúdo específico como é o caso de Cibber, que adapta uma peça criando outra peça - até uma série de viagens intersemióticas. Como explora a teórica pós-moderna Linda Hutcheon em seu livro Uma teoria da adaptação, o adaptador, ao colocar suas mãos sobre um texto fonte, tende a reproduzi-lo sem, no entanto, replicá-lo (HUTCHEON, 2011, p. 29). Hutcheon afirma que toda adaptação é "produto formal", "processo de criação" e "processo de recepção", sendo sempre premeditada pelas vias de um ato interpretativo. A escolha deliberada de uma ou mais obras e a sua paralela reinterpretação geram um novo produto cultural: um produto endividado e, ainda assim, ocasionalmente autônomo diante do texto fonte. Autonomia esta, porém, que contempla na esfera da recepção uma "estereofonia plural de ecos, citações e referências" (BARTHES, 1977b, p. 160), isto é, que contempla a adaptação como adaptação.

Sob a perspectiva materialista, dois aspectos trazidos por Hutcheon nos interessam de maneira mais imediata: a adaptação como "processo de criação", por um lado, e como "produto formal", por outro. Ou seja, respectivamente, o caráter de "transposição declarada de uma ou mais

\footnotetext{
${ }^{3}$ Consciente aqui da relação dialética entre o indivíduo e a sociedade, presente em todo tipo de produção ou reprodução da cultura - seja ela dominante, residual ou emergente (WILLIAMS, 1981).
} 
obras reconhecíveis" e o "ato criativo $e$ interpretativo de apropriação/recuperação" (HUTCHEON, 2011, p. 30). Uma vez abordados esses movimentos e atos, o "processo de recepção" da obra será de extrema relevância para a compreensão do movimento de reprodução cultural como instrumento a favor da continuidade de uma cultura. No entanto, antes de abordar o trabalho do dramaturgo Colley Cibber, é necessário compreender histórica e teoricamente como a cultura de seu tempo alimentou, estimulou e possibilitou a produção de sua adaptação shakespeariana: The Tragicall History of King Richard III (1700) $)^{4}$.

Resultado de uma Guerra Civil durante o reinado autocrático de Carlos I, a Inglaterra vivenciou, entre os anos de 1642 e 1660, aquilo que ficou conhecido nos anais da história inglesa como a República Puritana de Oliver Cromwell, ou Interregnum. Diante desse novo regime político, moralista e austero no que se refere aos costumes, a monarquia absolutista na Inglaterra encontrava-se terminantemente acabada - e assim fora declarada pelo Parlamento. No entanto, a morte de Cromwell em 1658 constaria na história como uma desarticulação interna decisiva para o fim dessa república, estimulando o retorno às terras inglesas do herdeiro ao trono real, Carlos II, membro da dinastia Stuart, exilado na França. A promoção da Restauração da monarquia inglesa alicerça-se, majoritariamente, em elementos culturais importados da França - gesto motivado pelo exílio de Carlos II na corte francesa. Alheios, portanto, às culturas imediatamente anteriores ao governo de Cromwell, esses elementos serão essenciais para a elaboração do que se convencionou denominar "teatro da Restauração". Da mistura dos escombros culturais de matriz inglesa com as novidades provindas do continente, a cultura da Restauração ganhará os ares de uma cultura própria.

Para compreender melhor essa enxurrada de mudanças radicais no panorama sociopolítico da Inglaterra, serão de grande auxílio teórico dois agrupamentos conceituais elaborados por Raymond Williams. O primeiro

\footnotetext{
${ }^{4}$ Doravante denominada $\mathrm{R} 3 \mathrm{Cb}$.
} 
agrupamento diz respeito às "culturas dominante, residual e emergente" e o segundo, às "estruturas de sentimento". Esses não são agrupamentos de caráter autônomo. Eles estão, portanto, intimamente relacionados entre si. Em seu livro Marxismo e literatura, Williams promove uma longa discussão acerca da conceituação histórica da hegemonia. Partindo de uma perspectiva materialista, a compreensão desse conceito é de suma importância para a consideração prática de como a cultura dominante configura-se no período da Restauração da monarquia inglesa. Interessa, para tal, o foco dado aos constantes processos de ressignificação e recriação, necessariamente modificadores e remodeladores da prática de qualquer hegemonia - afinal, "uma hegemonia vivida é sempre um processo. Não é, exceto analiticamente, um sistema ou uma estrutura. É um complexo realizado de experiências, relações e atividades, com pressões e limites específicos e mutáveis." (WILLIAMS, 1977, p. 115) Na mutabilidade de uma hegemonia reside a complexidade das margens produtivas: "A realidade de qualquer hegemonia, no sentido político e cultural ampliado, é de que, embora por definição seja sempre dominante, jamais será total ou exclusiva" (WILLIAMS, 1977, p. 116). Isso leva-nos aos conceitos de cultura residual e cultura emergente.

Etimologicamente, a palavra resíduo vem do latim residuum,-i, denotando "resto, restante". A cultura residual toma para si, portanto, um espaço que implica, por definição, um passado cultural e social. Se esse é mais ou menos distante do referencial dominante é uma preocupação de outra ordem, que, neste artigo, não nos cabe discutir. No entanto, a mera presença de elementos culturais e sociais do passado não acarreta, necessariamente, uma postura ativa por parte de tais elementos para com a cultura dominante. Ser resíduo de uma cultura passada infere alguma agência no processo cultural do presente - ainda que haja variações entre a diretividade dos modos de participação nesse processo ativo. Apesar do distanciamento dessa cultura residual em relação à cultura dominante efetiva, a realidade ativa de uma cultura é capaz de construir um campo vasto de possibilidades relacionais entre o que há de resíduo e aquilo que já 
se estabeleceu como dominante - desde procedimentos de incorporação ${ }^{5}$ até posturas alternativas ou oposicionistas à realidade dominante.

Quanto à cultura denominada emergente, pode-se dizer que seu ponto de partida é o pressuposto de que não há cultura absolutamente estanque - “(...) novos significados e valores, novas práticas, novas relações e tipos de relação estão sendo continuamente criados" (WILLIAMS, 1977, p. 126). Ainda assim, permanece o problema de se distinguir entre as formas que realmente pertencem à esfera da cultura emergente, em seu sentido rigoroso, e os elementos que representam apenas uma nova forma da cultura dominante (WILLIAMS, 1977, p. 126), discussão que retomaremos mais à frente.

As estruturas de sentimento, por outro lado, são "experiências sociais em solução, distintas de outras formações semânticas sociais que foram precipitadas e existem de forma mais evidente e imediata" (WILLIAMS, 1977, p. 136). Não se engana quem as observa como proclamadoras de pré-formações culturais. Estruturas que anunciam algo sem, de imediato, serem reconhecidas como práticas materiais. Estruturas que, a partir de um significativo distanciamento histórico, podem ser reconhecidas como "formações sociais e semânticas pela sua articulação de presença" (WILLIAMS, 1977, p. 137). O próprio Williams traz como exemplificação desse conceito a informação de que

Na Inglaterra entre 1660 e 1690 (...) duas estruturas de sentimento (entre os puritanos derrotados e a Corte restabelecida) podem ser facilmente identificadas, embora nenhuma das duas, em sua literatura e em outros pontos, seja redutível às ideologias desses grupos, ou às suas relações de classe formais (na verdade, complexas). (WILLIAMS, 1977, p. 136)

Estruturas de sentimento podem ser definidas como prefigurações complexas de uma cultura emergente ou, por vezes, de novas formas da

\footnotetext{
5 “Uma cultura residual está geralmente a certa distância da cultura dominante efetiva, mas é preciso reconhecer que. em atividades culturais reais, a cultura residual pode ser incorporada à dominante. Isto porque alguma parte dela, alguma versão dela - sobretudo se o resíduo é proveniente de alguma área importante do passado - terá de ser, em muitos casos, incorporada se a cultura dominante quiser fazer sentido nessas áreas. Também porque, em certos aspectos, uma cultura dominante não pode permitir que muitas dessas práticas e experiências fiquem fora de seu domínio sem correr certo risco." (WILLIAMS, 2005, p. 56-57)
} 
cultura dominante. No caso da Inglaterra da segunda metade do século XVII, a Restauração da monarquia recoloca em jogo uma hegemonia ditada pelo rei e, consequentemente, um movimento de efetivação de novas práticas culturais dominantes. Para Carlos II, é prioridade afirmar-se como monarca, em oposição ao recém-findo regime parlamentar de matriz puritana, comandado por Cromwell. A professora Liana Leão contribui para a construção de uma das faces da cultura nesse tempo ao pontuar como

Com o início da guerra civil em 1642, o Parlamento ordena o fechamento de lugares de diversão pública, entre os quais os teatros. Os atores sofrem perseguições ferozes o bastante para invocar as vagrancy laws, leis jacobinas contra a vadiação. As companhias teatrais se dispersam e todas as suas posses - roupas, livros de contra-regragem, objetos de cena, manuscritos de peças - são vendidas. Os edifícios teatrais são abandonados e destruídos pelo desuso. (LEÃO, 2001.2, p. 55-56)

O fechamento e a consequente demolição dos teatros é, no que tange à materialidade de um processo ativo, uma das manifestações culturais de maior impacto durante a república de Cromwell. Sendo assim, a monarquia restaurada acaba por estabelecer, necessariamente, uma prática cultural diretamente oposta. Parte da legitimação de uma coroa inglesa restaurada provém do teatro como ferramenta essencial no estímulo aos costumes de uma cultura monarquista. ${ }^{6}$ Com todas as suas peculiaridades, o teatro da restauração tem a sua matriz na importação de elementos da cultura francesa - a volta de Carlos II do exílio na França potencializa, portanto, uma mudança radical na arquitetura do edifício teatral e na maneira de apreciar o teatro.

Todo o deslocamento intercontinental da prática cultural neoclássica veio carregado do peso da "tradição": uma herança da aristocracia estrangeira cuidadosamente transmitida à corte de Carlos II durante seu desterro no continente europeu, subsequentemente assimilada pela aristocracia inglesa como a maneira "correta" de se apreciar e realizar a arte teatral. Um exemplo claro do que Raymond Williams nomeou de "tradição seletiva", ou seja,

\footnotetext{
6 “....) a mera retomada das atividades teatrais constitui um ato político que prova que o período do governo puritano avesso ao teatro definitivamente terminara." (LEÃO, 2001.2, p. 57)
} 
o que, nos termos de uma cultura dominante efetiva, é sempre assumido como 'a tradição', 'o passado significativo'. Mas sempre o ponto chave é a seleção - a forma pela qual, a partir de toda uma área possível do passado e do presente, certos significados e práticas são escolhidos e enfatizados, enquanto outros significados e práticas são negligenciados e excluídos. (WILLIAMS, 2005, p. 54) $^{7}$

Faz parte da base organizacional de um regime monárquico o estabelecimento de hierarquias internas. A escolha da tradição teatral vigente na França revela, para além de sua contraproposta ao regime puritano, um movimento dominante em busca de uma restrição das práticas culturais efetivas à elite aristocrática. Se ao tempo de Shakespeare as apresentações reuniram algo em torno de vinte e quatro mil espectadores semanais oriundos das mais diversas classes sociais, as casas de espetáculo ao tempo de Cibber não comportavam mais de 400 cortesãos por encenação (LEÃO, 2001.2, p. 58). Nesse decréscimo do contingente de espectadores teatrais reside um aspecto importante: os ingressos sofreram um aumento de custo exorbitante com a renovação das atividades dramáticas. A elitização do público implicou, portanto, uma declaração indireta de seletividade. Hierarquias sociais colocaram-se, de modo mais evidente, como afirmações de práticas culturais efetivas da cultura dominante. A cultura passa a transmitir a sensação de uma "continuidade predisposta" (WILLIAMS, 1977, p. 119) - que relega camadas específicas da sociedade, pondo-as à margem do processo cultural.

A retomada das atividades teatrais na Inglaterra é espontânea, uma vez que o retorno de Carlos II é iminente. Na cultura do neoclassicismo francês era hábito um espetáculo rico em música, cenário e figurino, sofisticado tecnologicamente e cujos artistas em cena emplacavam uma dicção elegante. Além do mais, por oposição à tradição teatral elisabetana dos "boy actors", era rotineiro o uso de mulheres para os papéis femininos. Esses fatores vinham acompanhados pelo costume, datado desde a época

\footnotetext{
7“A tradição é na prática a expressão mais evidente das pressões e limites dominantes e hegemônicos. É sempre mais do que um segmento inerte historicizado; na verdade, é o meio prático de incorporação mais poderoso. O que temos de ver não é apenas 'uma tradição', mas uma tradição seletiva: uma versão intencionalmente seletiva de um passado modelador e de um presente pré-modelado, que se torna poderosamente operativa no processo de definição e identificação social e cultural." (WILLIAMS, 1977, p. 118)
} 
do rei Jaime (1567-1625) ${ }^{8}$, de realizar espetáculos em espaços fechados para públicos da elite aristocrática - à guisa de exemplo, um antigo monastério desativado dentro dos limites da city londrina, o Blackfriars, se tornara, ao tempo de Jaime, o teatro que provavelmente recebeu as primeiras apresentações de peças como A Tempestade e Conto de Inverno. ${ }^{9}$ No entanto, com o advento do teatro da Restauração importa-se, também, um novo edifício teatral - decalcado a partir do palco italiano ${ }^{10}$, reconhecidamente popular na Europa. As construções voltadas para a realização de exibições teatrais eram apenas duas à época da Restauração - quadras de tênis convertidas em teatros, na realidade. Radicalmente diferente, porém, da estrutura elisabetana, a ascensão do palco italiano significa também o esquecimento - duradouro - da configuração cênica do palco avental, ao ar livre, rico em possibilidades e promotor de "grande intimidade entre plateia e atores, estes exclusivamente do sexo masculino" (LEÃO, 2001.2, p. 56).

No entanto, tal "exclusividade do sexo masculino" nos palcos elisabetanos e jaimescos é passível de questionamento - como demonstra Stephen Orgel em seu livro Impersonations: The performance of gender in Shakespeare's England:

[...] é verdade que as mulheres nunca apareciam nos palcos ingleses? A postulação, para começar, só pode se relacionar com o teatro público; mulheres comumente apareciam como dançarinas em mascaradas na corte ao longo dos períodos Elisabetano e Jacobino, e sob o patronato de Henrietta Maria, a rainha francesa de Carlos I, elas também ocupavam papéis com falas em peças na corte. (ORGEL, 1996, p. 3)

\footnotetext{
${ }^{8}$ Seu tempo como rei da Inglaterra vai de 1603 até a data da sua morte, 1625.

${ }^{9}$ Aqui cabe reproduzir na íntegra uma nota de rodapé pertencente ao texto da professora Liana Leão: "As inovações trazidas da França encontraram solo favorável na Inglaterra porque de certo modo não eram inteiramente novas no teatro inglês. Antes do fechamento dos teatros, precisamente com a moda das mascaradas na corte, as mulheres já haviam começado a participar em espetáculos e inclusive Charles I já havia sido criticado pelos puritanos por permitir a participação feminina. Os cenários elaborados também já estavam sendo cultuados, preconizando a ênfase futura na elaboração cênica. Além disso, os teatros menores e privados já começavam a funcionar, como o próprio Blackfriars, exigindo modificações nas peças para serem acomodadas em espaços menores; estes teatros já contavam com alguns efeitos rudimentares produzidos por luz de vela. A música já começava a dominar as novas produções." (LEÃO, 2001.2, p. 53)

10 “(...) o uso do palco italiano maior e com cortinas - onde a ação se passa atrás do proscênio e bem mais distante da platéia que no teatro elisabetano (...)" (LEÃO, 2001.2, p. 57)
} 
A exposição de Orgel prossegue sob a tese de que o problema não se devia ao impacto que mulheres atuando poderiam ter nas plateias da época, mas uma séria questão se colocava quando elas se autoproclamavam atrizes por profissão, havendo uma associação imediata de promiscuidade a essas mulheres. Em países como a França e a Espanha, pelo menos oficialmente, resolvia-se o assunto da castidade feminina exigindo que as mulheres em cena fossem casadas. O teatro era, afinal,

[...] uma ameaça para a masculinidade e estabilidade das hierarquias sociais, conforme mulheres desacompanhadas e homens sem suas esposas socializam livremente, e (como consequência) flertavam uns com os outros e levavam uns aos outros para a cama: a associação do teatro com sexo é absolutamente impregnada por essas polêmicas. (ORGEL, 1996, p. 26)

Observa-se, dessa forma, como a relativa liberalização do envolvimento das mulheres em tais práticas culturais era um fenômeno particular da classe média londrina na Renascença ${ }^{11}$. "[...] isso certamente corresponde mutuamente à popularidade do teatro londrino com as mulheres, e à relativa liberdade [das mulheres] para usufruí-lo: o teatro profissional tirava muito de seu suporte das classes mercantis e artesãs de Londres" (ORGEL, 1996, p. 37). O sentimento geral, porém, é o típico de sociedades organizadas por uma estrutura patriarcal - "medo de perder o controle sobre a castidade das mulheres, uma posse de muito valor que garantia a legitimidade de um herdeiro, e especialmente valioso para os pais como um pedaço de propriedade descartável" (ORGEL, 1996, p. 36).

Orgel, portanto, indica uma mudança de paradigma com a incorporação oficial das atrizes nos palcos ingleses. Há resíduos de uma cultura anterior à Restauração, em que atrizes faziam parte das trupes italianas e circulavam pela corte inglesa, viajando pelo país com a Rainha Elisabete. A cultura aristocrata tornou-se a única, ou ao menos a mais proeminente (dominante), propagadora do novo teatro, importado dos franceses. Dessa maneira, as ansiedades patriarcais da Renascença

\footnotetext{
${ }^{11} \mathrm{O}$ conceito de Renascimento Inglês como compreendido neste artigo alinha-se às pesquisas do acadêmico britânico Stephen Orgel - em particular às acepções trazidas em seu livro, Impersonations: The performance of gender in Shakespeare's England.
} 
encontram um solo fértil na Restauração e o teatro como um espaço de liberdade para as mulheres desaparece. $\mathrm{O}$ fator econômico dessa transição é, portanto, altamente panóptico - mais do que um retorno à rejeição das atrizes, o movimento na corte é de vigilância sobre o comportamento de quem está na plateia.

No que se refira, porém, ao cotidiano dos grupos teatrais, duas companhias dividiam a cena teatral da Restauração: The King's Company, atrelada ao patronato do rei Carlos II e comandada por seu companheiro de exílio Thomas Killigrew, e The Duke's Men, vinculados ao Duque de York, cujo líder era Sir William Davenant. Este último, como nos aponta o crítico Christopher Spencer, "durante a Restauração, provou-se ansioso por mostrar à nova corte e a uma geração mais jovem que seu gosto estava atualizado e que Shakespeare, imensamente admirado por ele [Davenant], poderia ser feito de forma mais atraente para os novos padrões de teatro" (SPENCER, 1965, p. 1). Isto é, adaptar e alterar o Bardo seguindo os preceitos da reforma estética operada pela Restauração. Dentre as diversas prescrições da proposta neoclássica francesa, a atualização da linguagem torna-se prática adaptativa corrente, devido à "língua inglesa [ter] se modificado em relação ao inglês elisabetano e jaimesco - [promovendo] um novo contexto cultural [que] exigia alterações nos textos de Shakespeare, inaugurando uma prolífica onda de adaptações de suas peças" (CARNEIRO, 2014, p. 30). Spencer ainda comenta que "a adaptação típica [na Restauração] inclui um corte substancial de cenas, falas e atribuições das falas; muita alteração de linguagem; e ao menos uma, geralmente várias, adições (de cenas)" (SPENCER, 1965, p. 7).

Assim sendo, essa tradição teatral de origem francesa encontra em Shakespeare um pilar. Como nos indica a publicação do Primeiro Fólio (1623) de suas "obras completas"12, sete anos após sua morte, Shakespeare já era um autor amplamente reconhecido no período jaimesco, e será continuamente resgatado ao longo de todo o período da Restauração, dada a carência de dramaturgos contemporâneos que suprissem as demandas da

\footnotetext{
${ }^{12}$ Apenas trinta e seis das em torno de 40 peças hoje atribuídas a Shakespeare foram publicadas no fólio de 1623.
} 
nova tradição teatral. Spencer aponta como "Dryden"13 dizia, [que] Shakespeare é um gênio extraordinário; mas sua grandeza está enterrada embaixo da linguagem não sofisticada de seus dias, de enredos que precisam ser remodelados, de uma sucessão incoerente de cenas, e de um desenvolvimento de personagens desnecessário e incompleto" (SPENCER, 1965, p. 10). Em vista disso, Shakespeare pode ser lido como um grande exemplo de cultura residual assimilada por uma cultura dominante. Williams afirma que "o residual, por definição, foi efetivamente formado no passado, mas ainda está ativo no processo cultural, não só como um elemento do passado, mas como um elemento efetivo do presente" (WILLIAMS, 1977, p. 125). A reativação de Shakespeare, o Bardo do período elisabetano, ocorre subsequentemente ao longo da história pelas vias da adaptação. De Colley Cibber (1671 - 1757) a David Garrick (1717 1779), de Thomas Bowdler (1754 - 1825) a Sir Ian Mckellen (1939 - presente data), os palcos e as telas de cinema estão repletos de Shakespeare.

Segundo a introdução de James R. Siemon para a edição da Arden Shakespeare de R3Skp, “a Restauração de Carlos II em 1660 trouxe a reabertura dos teatros, mas a evidência que sobrevive é de apenas duas produções antes da peça de Shakespeare se tornar - pelos próximos cento e cinquenta anos - de Cibber" (SIEMON, 2009, p.86). A estética neoclássica colide com a linguagem do tempo de Shakespeare gerando severas críticas à sua sintaxe complexa, à sua "exuberância na invenção de palavras" e recomendando um gesto de moderação por parte daqueles que se propunham dramaturgos - ao tempo da Restauração, quase um sinônimo para adaptadores. A adaptação é um recurso criador e criativo, e como produto cultural do período da Restauração, busca por autonomia. ${ }^{14}$ No

\footnotetext{
13 John Dryden (1631-1700) foi um poeta, crítico literário, tradutor e dramaturgo que dominou a cena literária do período da Restauradação da Monarquia Inglesa a ponto do período passar a ser denominado, por alguns círculos literários, como "A Era de Dryden".

14"Pode-se objetar que essas peças da Restauração foram escritas e executadas como se fossem Shakespeare 'alterado ou adaptado, e que, portanto, a abordagem que sugiro não é natural. No entanto, parte da nossa incapacidade de ver muitos elogios direcionados às adaptações vem das falsas expectativas estabelecidas pelas palavras 'alteração' e 'adaptação'. Elas parecem sugerir que um original está sendo ajustado apenas o necessário para atender a novas condições; e os próprios adaptadores contribuíram para esse mal-entendido dizendo que estão meramente lapidando as jóias de Shakespeare, que ele era muito ignorante (ou que ele viveu em uma época muito ignorante) para se polir. Não obstante, é certamente verdade que muitas vezes fizeram mais do que 'alterar' ou 'adaptar' ou 'lapidar
} 
caso de Cibber, sua construção da personagem Ricardo III realmente ganhou vida própria -

em 1740 o Ricardo III de Cibber [R3Cb], já havia sido encenado oitenta e quatro vezes, ocorrendo virtualmente em todas as temporadas, às vezes em duas ou três casas [de espetáculo]; a peça recebeu elogios por sua exposição clara e concentrada, acelerado tempo de apresentação, escalação simplificada e ação que se constrói em direção a uma inflamada batalha. (SIEMON, 2009, p. 88)

Ainda na introdução de Siemon é pontuado como, "apesar da aparição das primeiras edições acadêmicas, contemporâneos aclamaram a versão de Cibber por sua 'compacidade', 'introdução clara e simples' e elevado 'espírito' nos atos finais”' (SIEMON, 2009, p. 87).

Duas passagens são exemplares de alguns dos aspectos formais de $R 3 C b$ : a primeira envolve um apelo explícito à clareza discursiva em relação aos laços familiares historicamente localizados; já a segunda, diz respeito aos elementos retirados de Shakespeare e assinalados nas edições impressas do texto de Cibber - de acordo com a vontade do próprio adaptador, como escreve em seu Prefácio. A respeito do primeiro tópico, na preparação para a entrada de Lady Ann, no segundo ato de Cibber, vemos o seguinte diálogo:

Tress.: I am oblig'd to pay Attendance here,

The Lady Ann has license to remove

King Henry's Corps to be Interr'd at Chertsey,

And I am engag'd to follow her.

Ld. Stanley: Mean you King Henry's Daughter-in-Law?

Tress.: The same, Sir, Widow to the late Prince Edward,

Whom Gloucester kill'd at Tewkesbury. (2.1.20 - 25)

(CIBBER, 1965, p. 293)

Além de colocar em evidência as relações genealógicas da personagem que entrará logo em seguida, a passagem é integralmente

preciosidades' no sentido que essas palavras geralmente têm para nós; e podemos julgar mais razoavelmente em termos do que eles fizeram do que daquilo que muitas vezes disseram que fizeram." (SPENCER, 1965, p. 9) 
grafada em itálico como sendo de autoria do próprio Cibber. Trata-se, portanto, de uma passagem construída segundo alguns dos moldes legisladores de novos requisitos para o "bom teatro", seu principal aspecto sendo as adições de falas que priorizam concisão e clareza na peça.

Acerca do segundo tópico, Siemon nos alerta que "Cibber adicionou passagens das três partes de Henrique VI, Ricardo II, Henrique V e das duas partes de Henrique $I V$, centenas de novos versos, novos incidentes, novo pathos e novas ênfases." (SIEMON, 2009, p. 89) Bebendo largamente nas peças históricas de Shakespeare, certas falas são realocadas por completo prezando por algum paralelo contextual. Por exemplo, Cibber toma a fala de abertura da peça Henrique VI Parte I (1590) e transfere-a do luto de Bedford durante o funeral de Henrique $\mathrm{V}$ para o de Lady Ann durante o funeral de Henrique VI:

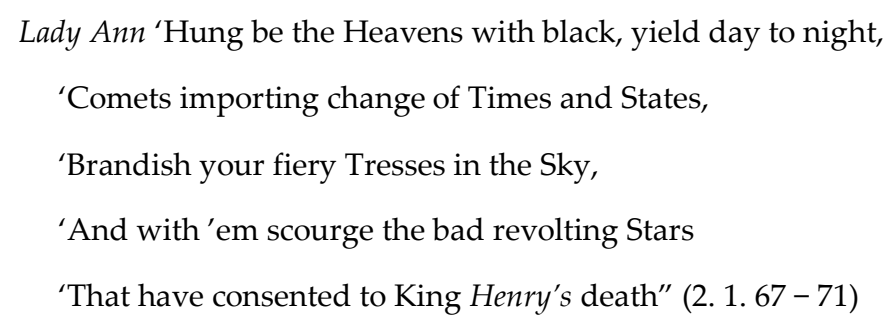

(CIBBER, 1965, p. 294)

Seguindo adiante em nossa análise, é curioso ver como alguns textos críticos a respeito de $R 3 S k p$ também encontram ressonância se confrontados com o texto de $\mathrm{R} 3 \mathrm{Cb}$. A crítica feminista Madonne M. Miner ilustra bem essa afirmação quando, em seu ensaio intitulado Neither Mother, Wife, Nor England's Queen, aponta, em relação a R3Skp, como

Todas essas mulheres [Lady Ann, Rainha Elizabeth, Margaret, Duquesa de York] sofrem, em alguma medida, uma perda de definição nas mãos de Ricardo. Presas em uma sociedade que concebe as mulheres estritamente em termos relacionais (isto é, como esposas para seus maridos, mães para seus filhos, rainhas para seus reis), as mulheres estão sujeitas a uma perda de título, posição, e identidade, conforme Ricardo destrói aqueles por quem as mulheres são definidas: maridos, filhos, reis. (MINER, 1983, p. 41) 
Essa observação encontra respaldo igualmente no texto de Cibber, quando o autor reproduz, quase integralmente, a cena do cortejo de Lady Ann como escrita por Shakespeare. Suas adições são relativas a esclarecimentos genealógicos e realocações textuais com fins de intensificar algum aspecto da cena, como demonstrado pelos exemplos acima. Seus cortes enxugam a cena sem danificar seu movimento principal. Por movimento principal, aqui, entendemos as duas estratégias de Ricardo que convergem nesse episódio - i) o apagamento da identidade de Ann por meio do assassinato de seu marido e sogro e ii) a realocação da culpa de seus assassinatos, não no assassino, Ricardo, mas no que o teria motivado a agir, seu amor por Ann. Analisando essa cena em R3Skp, Miner afirma que

Ao focar em sua beleza, Ricardo insiste que Anne se encaixa na definição
bem plana de 'mulher' que ele mesmo articulou em seu solilóquio de
abertura - uma definição que divide o mundo em províncias de
masculino e feminino, negando ao último qualquer possibilidade de
comunhão com emblemas (como espadas) do primeiro. Focando-se na
culpa de Anne, Ricardo desvia a responsabilidade de si mesmo e constrói
um vínculo de aliança entre Anne e ele (...) tornando-a impotente.
(MINER, 1983, p.38)

Cibber nos fornece, ao menos, duas outras situações com traços semelhantes - o momento, no final do segundo ato, em que a Rainha Elizabeth aparece de luto pelo recém-falecido marido, Eduardo IV, e a primeira cena do quarto ato, em que ela se despede de seus filhos. $\mathrm{Na}$ primeira situação, a entrada da Rainha pesarosa equivale a uma fala de oito versos seguida de uma violenta realocação identitária por parte de Stanley,

Your duty, Madam, of a Wife is Dead,

And now the Mother's only claims your care.

Think on the Prince your Son: send for him strait,

And let his Coronation clear your eyes. (2. 2. 52-55)

(CIBBER, 1965, p. 301)

Ou seja, a maternidade passará a ser a leitura imediata de Elizabeth, não mais identificada por seu papel como Rainha ou como esposa. Dessa forma, estabelece-se, explicitamente, uma nova identidade para Elizabeth. 
O comunicado faz pleno sentido se o consideramos como a exposição de uma realidade cultural efetiva. Aqui se insere o resgate histórico cultural fascinante realizado por Stephen Orgel ao salientar que “as mulheres são definidas nessa cultura [do início da Era Moderna inglesa, portanto à época na qual Shakespeare escreveu $R 3 S k p$ ] em suas relações com os homens, no entanto, suas distinções de gênero são fluidas e pouco claras" (ORGEL, 1996, p. 13). Parece que, enquanto a maneira de definir a identidade das mulheres foi incorporada pela cultura dominante no período da Restauração, a fluidez de gênero se atrofiou. A presença das atrizes em cena e o consequente declínio gradual da presença dos "boy actors" no teatro da Restauração serviram como catalisadores para uma política de gênero pautada na fixidez e no binarismo. $O$ desaparecimento da Rainha Margaret em $\mathrm{R} 3 \mathrm{Cb}$ - de que trataremos adiante - é, em parte, consequência dessa atrofia.

$R 3 C b$ traz uma mudança crucial na segunda situação analisada acima. Em uma cena inédita, os dois príncipes, dentre os quais um é herdeiro do trono, encontram-se na Torre por ordens de Ricardo, e recebem uma visita da mãe, Elizabeth. Cibber introduz um desdobramento decorrente da chegada de um tenente que notifica Elizabeth da proibição de visitantes na Torre. Ocorre, então, uma despedida na qual fica implícito que o destino das duas crianças é a morte. Além de a cena ser de grande apelo para o público da Restauração e acentuar a identidade materna de Elizabeth, ela é prefigurada pela ordem social patriarcal presente desde as fontes de Cibber na tetralogia de peças históricas escritas por Shakespeare, ou seja, desde o Renascimento. Na primeira cena de Henrique VI Parte 3, a Rainha Margaret, ao saber do compromisso assumido pelo Rei Henrique, segundo o qual transferiria a herança do trono real para a linhagem dos York, esbraveja

\footnotetext{
Had I been there, which am a silly woman,

The soldiers should have tossed me on their pikes

Before I would have granted to that act.

But thou preferre'st thy life before thine honour:

And seeing thou dost, I here divorce myself
} 
Both from thy table, Henry, and thy bed,

Until that act of parliament be repealed

Whereby my son is disinherited. (1.1.245-252)

(SHAKESPEARE, 1993, p. 83)

O que é a vontade de uma mãe em face à de um rei? "I am their Mother, Sir, who else commands 'em?" (CIBBER, 1965, p. 319), questiona Elizabeth quando é proibida de visitar seus filhos. Ao que o tenente responde, pouco depois, "Such are the King's Commands, Madam" (CIBBER, 1965, p. 319). Mais ao final do quarto ato, em $R 3 C b$, a Duquesa de York clama, "I have a Mother's right, I'll force him hear me" (CIBBER, 1965, p. 326), mas Ricardo dá pouca atenção às falas da mãe. O paralelismo entre essas cenas se dá no âmbito de uma sólida hierarquia entre gênero e identidades sociais - estrutura incorporada por uma prática cultural efetiva da Restauração, como vemos no próprio Cibber. Identitariamente, o rei é um símbolo maior, atrelado - na maioria dos casos - ao homem. Mesmo aquela que é considerada a representante máxima de subversão da identidade feminina nas peças históricas de Shakespeare, a Rainha Margaret, falha na tentativa de usurpação da identidade masculina do rei em seus termos políticos, isto é, parlamentares - no campo de batalha ela representava aquele que deveria comandar os exércitos ingleses, mas na corte, Henrique ainda era o rei. "A roupa era a realidade; (...) Roupas faziam a mulher, roupas faziam o homem: o figurino denunciava a essência." (ORGEL, 1996, p. 104) O esforço de reivindicação discursiva do gênero oposto faz de Margaret uma personagem transgressora, mas as práticas culturais do tempo em que Shakespeare escreveu a sua Henríada tem por convenção a ideia da vestimenta que denota essência.

Se Cibber considerava que a jornada de Margaret D'Anjou teria início em Henrique VI Parte 1, pode ter escolhido excluí-la da peça pelo quão explicitamente ela se implica em ansiedades comuns aos homens, datadas do tempo de Shakespeare, mas incorporadas pela cultura da Restauração. Por exemplo, a ameaça das mulheres, sem as restrições do patriarcado, traírem seus maridos - materializada no affair de Margaret com Suffolk. Outra questão poderia ter surgido a partir da observação de 
que no quinto ato de Henrique VI Parte 3, duas indicações são feitas acerca das possibilidades futuras para Margaret:

a) Rich. Why should she live to fill the world with words.

b) Clarence. What will your grace have done with Margaret?

Reiginier, her father, to the King of France

Hath pawned the Sicils and Jerusalem,

And hither have they sent it for her ransom.

King Edward. Away with her and waft her hence to France!

A primeira alternativa antecipa sem, entretanto, determinar o caminho a-histórico da personagem, desenvolvido por Shakespeare em R3Skp. A segunda, por outro lado, apontando um caminho mais fiel às crônicas históricas de Raphael Holinshed e Edward Hall, oferece um desfecho concreto para Margaret. A personagem teria sua jornada concluída no quinto ato de Henrique VI Parte $2^{15}$, portanto, ela serviria apenas como mais estofo histórico indesejado e repudiado pela poética neoclássica do tempo da Restauração. Ela seria, para uma peça que busca clareza e simplificação histórica, minimamente, uma complicação enfadonha que atrapalha o estabelecimento de Ricardo como vilão absoluto. Mais interessante, no entanto, é pensar como Margaret parece estar antes próxima de uma concretização exemplar do que Orgel aponta na Renascença como

uma ideologia que contém suas contradições ao permiti-las como contradições; as contradições - que parecem ameaçar a ideologia - são essenciais para a própria, são o que a fazem funcionar. Enxerga a si mesma como em constante perigo, e exerce seu poder por sempre descobrir repetições de uma primeira queda do paraíso, a qual, sendo este um patriarcado, foi uma rebelião contra o pai. (ORGEL, 1996, p. 124)

Margaret D'Anjou encarna, em R3Skp, a posição de antagonista ao governo e, principalmente, à personagem de Ricardo III. Uma vez que Margaret foi testemunha do assassinato de seu filho pelas mãos de Ricardo

\footnotetext{
${ }^{15}$ Cronologicamente, a primeira tetralogia histórica escrita por Shakespeare - na qual acompanhamos, em um de seus planos narrativos, a história de Margaret D'Anjou - é composta das três partes de Henrique VI (1590 - 1592) e Ricardo III (1592).
} 
- conforme Shakespeare dramatiza em Henrique VI Parte 3 -, ela já sabe do que o vilão é capaz. Dessa forma, sua função dramática em R3Skp a dispõe em cena à semelhança de um resistente obstáculo cuja presença atesta o que há de pior em Ricardo. Sua mera aparição nos fundos da cena, utilizandose de "apartes", opera como um lembrete ao leitor/espectador de que uma oposição à ideologia vigente permanece sempre à espreita.

A organização da plateia no teatro elisabetano favorece a ocorrência de personagens como Margaret. Uma vez que parte considerável do público era, segundo Orgel (1996), composto por mulheres, existe por trás desse favorecimento uma razão econômica - "representações teatrais sejam de mulheres ou homens ou qualquer outra coisa - também dependiam para o seu sucesso de um alto grau de receptividade por parte das mulheres." (ORGEL, 1996, p.11) Margaret faz parte de uma gama de personagens femininas construídas sobre as bases de fantasias culturais comungadas pelas espectadoras da Renascença.

Para uma audiência feminina, em uma cultura tão estratificada pelo patriarcado como aquela da Inglaterra Renascentista, ver a juventude [masculina] em saias poderia significar o seu desarmamento e sua socialização à moda especificamente feminina, vê-los não como mestres ou donos, mas como sociáveis e maleáveis, um entre elas. (ORGEL, 1996, p.81)

Durante o período da Restauração, entretanto, a postura é inteiramente outra. Não só a fluidez de gênero, desestimulada com a diminuição de "boy actors" em cena, passa a ser atrofiada em categorias mais fixas, mas também a agenda política da ciência da época contribui para enraizar crenças já correntes na Renascença de que "mulheres são menos inteligentes, mais emotivas, tem menos controles sobre suas paixões, e daí em diante." (ORGEL, 1996, p. 25) Compreende-se, assim, que o ator travestido era indispensável para a Inglaterra Renascentista; mas (ou, talvez, portanto) a sua figura nunca foi completamente naturalizada. Ele era essencial precisamente como um construto, sempre disponível para interrogar, deslocar, reinterpretar as normas, que eram sempre concebíveis como instáveis - a interrogação, portanto, era uma parte essencial da eterna tentativa de estabilização. (ORGEL, 1996, p. 108)

Sem uma substituta adequada para Margaret, em $\mathrm{R} 3 \mathrm{Cb}$ temos apenas um vislumbre de consciência no lado das personagens femininas. 
Decididas a confrontar Ricardo com suas palavras de ódio, a Elizabeth e a Duquesa de York de Cibber carecem da força implicada pelas falas de Margaret frente ao vilão. Margaret as conscientiza violentamente, em $R 3 S k p$, do que significa viver sob o peso de um contexto no qual ser viúva e conviver com a morte dos filhos as destitui de uma identidade própria. Ela o faz, justamente, após os homens à sua volta - que a permitiam ser reconhecida como esposa e mãe - terem perecido nas mãos de Ricardo. Tal contraste entre as personagens femininas de R3Skp leva Miner a fazer o comentário de que

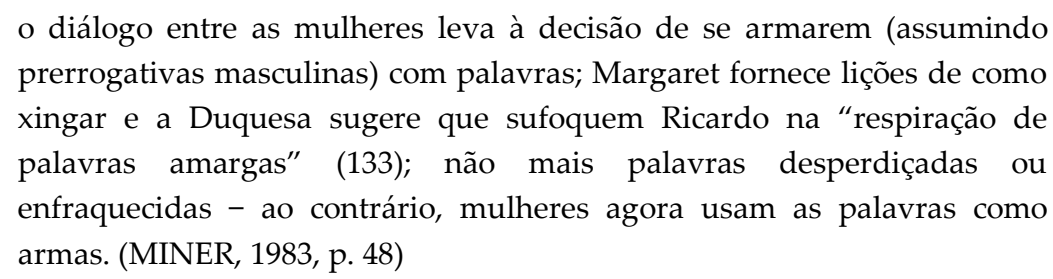

As práticas culturais são outras, a lógica por trás da efetivação da cultura na Restauração é outra. Não mais as mulheres poderão viver para amaldiçoar os homens se as implicações dessas maldições forem reais muito menos se essas mulheres carregam em si a materialização dos anseios do patriarcado. Comentando uma passagem de matriz teológica escrita pelo intelectual puritano John Rainoldes (1549-1627), contemporâneo de Shakespeare, Stephen Orgel sugere que

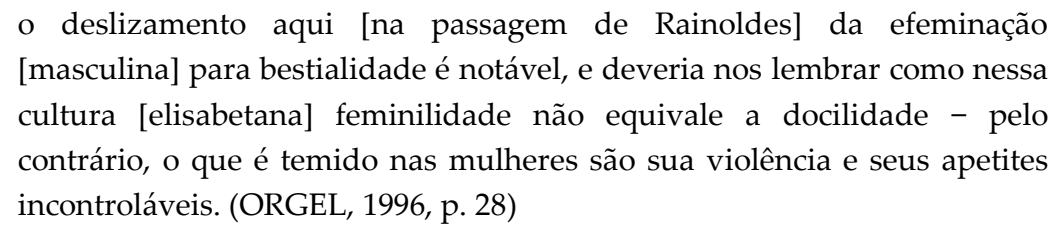

A ausência de Margaret parece acarretar, portanto, uma diminuição na ameaça ao protagonismo de Ricardo. Afinal, enquanto a Duquesa de York aposta no seu direito de mãe ao aventurar-se em um confronto discursivo com Ricardo, Margaret já reconheceu há muito tempo que, para a lábia de Ricardo, resta apenas o xingamento. Sua eliminação não é ocasional, mas talvez seja uma consequência menos direta do que gostaríamos de imaginar. Ela é, todavia, sintomática.

Essa emancipadora liberdade teatral [das mulheres pertencentes à classe média londrina que compunham parte considerável do público da época], no entanto, poderia também ser vista como perigosa e anárquica, e a fonte 
do perigo era [...] tomada como sendo de matriz especificamente sexual. [e.g. ansiedades do patriarcado relativas ao adultério] (ORGEL, 1996, p. 37)

O apagamento de Margaret carrega, portanto, em si, o poder de insinuar um alinhamento à síntese de Orgel sobre o período - "as propriedades de gênero têm tudo a ver com as propriedades de classe social" (ORGEL, 1996, p. 108). Assim sendo, a representação na cena teatral inglesa de mulheres como Margaret, que afrontam a ideologia patriarcal e anunciam o adultério como possibilidade, torna-se um terreno fértil para o crescimento das ansiedades dessa classe média londrina cujas mulheres compõem "parte considerável do público da época".

\section{Referências}

BARTHES, Roland. From Work to text. In: BARTHES, Image - Music Text. Trans. Stephen Heath. New York: Hill \& Wang, 1977b, p. 155- 164. CARNEIRO, Leonardo Bérenger Alves. "Thy name is woman": a (re)construção das identidades femininas em adaptações narrativas de Hamlet. Rio de Janeiro, 2014. Tese de Doutorado em Pós-Graduação em Linguística Aplicada - Universidade Federal do Rio de Janeiro, mimeo.

CIBBER, Colley. The Tragicall Historie of Richard III. (p. 275 - 344). In: SPENCER, Christopher, (Ed.). Five Restoration Adaptations of Shakespeare. Urbana: University of Illinois Press, 1965.

HUTCHEON, Linda. Uma teoria da adaptação. Trad. André Cechinel. Florianópolis: Editora UFSC, 2011.

LEÃO, Liana de Camargo. Shakespeare na Restauração: a ilha encantada de Dryden e Davenant, uma adaptação de $A$ Tempestade. Revista Crop (FFLCH/USP), Humanitas/FFLCH/USP SP, v. 7, n. 1, 2001. p. 53-82.

MINER, Madonne M. 'Neither Mother, Wife, Nor England's Queen': The Roles of Women in Richard III. In: LENZ, Carolyn Ruth Swift; GREENE, Gayle \& NEELY, Carol Thomas (Eds.). The Woman's Part. Feminist Criticism of Shakespeare. Urbana, Chicago, London: University of Illinois Press, 1983, p. $35-55$. 
ORGEL, Stephen. Impersonations: The performance of Gender in Shakespeare's England. Cambridge: Cambridge University Press, 1996. SHAKESPEARE, William. The First Part of King Henry VI. Ed. Michael Hattaway. The New Cambridge Shakespeare. Cambridge: Cambridge University Press, 1990.

The Second Part of King Henry VI. Ed. Michael Hattaway. The New Cambridge Shakespeare. Cambridge: Cambridge University Press, 1991.

The Third Part of King Henry VI. Ed. Michael Hattaway. The New Cambridge Shakespeare. Cambridge: Cambridge University Press, 1993.

King Richard III. Ed. James R. Siemon. The Arden Shakespeare. Third Series. London: Bloomsbury, 2009.

SIEMON, James R. Introduction (p.1 - 23). In: SHAKESPEARE, William. King Richard III. Ed. James R. Siemon. The Arden Shakespeare. Third Series. London: Bloomsbury, 2009.

SPENCER, Christopher (Ed.). Five Restoration Adaptations of Shakespeare. Urbana: University of Illinois Press, 1965.

WILLIAMS, Raymond. Marxismo e Literatura. Trad. Waltensir Dutra. Rio de Janeiro: Zahar Editores, 1979.

Cultura e Materialismo. Trad. André Glaser. São Paulo: Editora Unesp, 2005.

Culture. London: Fontana, 1981.

\section{Resumo}

Entrelaçando o materialismo cultural à teoria feminista, nosso objetivo é compreender o contexto histórico no qual se insere o dramaturgo-adaptador Colley Cibber (1671 - 1757) quando de sua reconstrução de uma personagem - (Rainha) Margaret D'Anjou - de Shakespeare em The Tragicall Historie of Richard III (1700). Portanto, nossa análise da peça alicerça-se na revisão dos papéis socioculturais exercidos pelas mulheres durante ambas Inglaterras, de Elisabete I e de Carlos II, com o intuito de realizar uma leitura empoderadora dessas personagens na peça 
shakespeariana, King Richard III (1592). Se a posição ocupada pelas mulheres na Inglaterra elisabetana repercutiu diretamente na maneira como elas foram retratadas na obra de Shakespeare, a ausência da Rainha Margaret em relação às outras personagens femininas na peça de Cibber deve ser levada em consideração pelo crítico da adaptação.

Palavras-chave: William Shakespeare; adaptação; Teatro da Restauração.

\begin{abstract}
Intertwining cultural materialism and feminist theory, our objective is to understand the background of Restoration Theater playwright-adaptor Colley Cibber (1671 - 1757) when reconstructing Shakespeare's Queen Margaret in The Tragicall Historie of Richard III (1700). Therefore, our analysis of the play is structured upon a historical revision of women's roles during Elizabethan and Charlesian Englands, and aims at a female-empowering reading of Shakespeare's King Richard III (1592). If women's position in society during Shakespeare's England reflected directly on their portrayal in his plays, Queen Margaret's absence alongside the other female roles in Cibber's play must be taken into consideration by the critic of the adaptation.
\end{abstract}

Palavras-chave: William Shakespeare; adaptation; Restoration Drama. 